\title{
Palmitic Acid
}

National Cancer Institute

\section{Source}

National Cancer Institute. Palmitic Acid. NCI Thesaurus. Code C61873.

A saturated long-chain fatty acid with a 16-carbon backbone. Palmitic acid is found naturally in palm oil and palm kernel oil, as well as in butter, cheese, milk and meat. 